\title{
Infection Patterns and Fitness Effects of Rickettsia and Sodalis Symbionts in the Green Lacewing Chrysoperla carnea
}

\author{
Rebekka Sontowski ${ }^{1,2}$, Michael Gerth ${ }^{3}{ }^{\oplus}$, Sandy Richter ${ }^{4,5}{ }^{\oplus}$, Axel Gruppe ${ }^{6}(\mathbb{C}$, \\ Martin Schlegel 1,5 ${ }^{1 D}$, Nicole M. van Dam ${ }^{1,2} \mathbb{D}$ and Christoph Bleidorn 1,7,* \\ 1 German Centre for Integrative Biodiversity Research (iDiv) Halle-Jena-Leipzig, 04103 Leipzig, Germany; \\ rebekka.sontowski@idiv.de (R.S.); schlegel@uni-leipzig.de (M.S.); nicole.vandam@idiv.de (N.M.v.D.) \\ 2 Institute of Biodiversity, Friedrich-Schiller-University, 07743 Jena, Germany \\ 3 Department of Biological and Medical Sciences, Oxford Brookes University, Oxford OX3 0BP, UK; \\ mgerth@brookes.ac.uk \\ 4 Department of Basic and Clinical Neuroscience, King's College London, 5 Cutcombe Road, \\ London SE5 9RT, UK; sr.sandyrichter@gmail.com \\ 5 Institute of Biology, Molecular Evolution and Systematics of Animals, University of Leipzig, \\ 04109 Leipzig, Germany \\ 6 Chair of Zoology_Entomology Group, Technical University of Munich, 85354 Freising, Germany; \\ gruppe@wzw.tum.de \\ 7 Animal Evolution and Biodiversity, Georg-Augustus-University, 37073 Göttingen, Germany \\ * Correspondence: cbleido@gwdg.de; Tel.: +49-5513925459
}

Received: 6 November 2020; Accepted: 4 December 2020; Published: 7 December 2020

Simple Summary: Bacteria have occupied a wide range of habitats including insect hosts. There they can strongly affect host physiology and ecology in a positive or negative way. Bacteria living exclusively inside other organisms are called endosymbionts. They often establish a long-term and stable association with their host. Although more and more studies focus on endosymbiont-insect interactions, the group of Neuroptera is largely neglected in such studies. We were interested in the common green lacewing (Chrysoperla carnea), a representative of Neuroptera, which is mainly known for its use in biological pest control. We asked ourselves which endosymbionts are present in these lacewings. By screening natural and laboratory populations, we found that the endosymbiont Rickettsia is present in all populations but the symbiont Sodalis only occurred in laboratory populations. We were curious whether both endosymbionts affect reproduction success. Through establishing and studying green lacewing lines carrying different endosymbionts, we found that Rickettsia had no effect on the insect reproduction, while Sodalis reduced the number of eggs laid by lacewings, alone and in co-infections with Rickettsia. The economic and ecological importance of green lacewings in biological pest control warrants a more profound understanding of its biology, which might be strongly influenced by symbionts.

Abstract: Endosymbionts are widely distributed in insects and can strongly affect their host ecology. The common green lacewing (Chrysoperla carnea) is a neuropteran insect which is widely used in biological pest control. However, their endosymbionts and their interactions with their hosts have not been very well studied. Therefore, we screened for endosymbionts in natural and laboratory populations of $\mathrm{Ch}$. carnea using diagnostic PCR amplicons. We found the endosymbiont Rickettsia to be very common in all screened natural and laboratory populations, while a hitherto uncharacterized Sodalis strain was found only in laboratory populations. By establishing lacewing lines with no, single or co-infections of Sodalis and Rickettsia, we found a high vertical transmission rate for both endosymbionts ( $>89 \%)$. However, we were only able to estimate these numbers for co-infected lacewings. Sodalis negatively affected the reproductive success in single and co-infected Ch. carnea, 
while Rickettsia showed no effect. We hypothesize that the fitness costs accrued by Sodalis infections might be more tolerable in the laboratory than in natural populations, as the latter are also prone to fluctuating environmental conditions and natural enemies. The economic and ecological importance of lacewings in biological pest control warrants a more profound understanding of its biology, which might be influenced by symbionts.

Keywords: biological pest control; co-infection; endosymbiont; Neuroptera; Rickettsiales; symbiosis

\section{Introduction}

With about 6000 species Neuroptera represents a rather small group of insects [1]. One well-known representative of the Neuroptera is the common green lacewing Chrysoperla carnea. Originally assumed to represent a single species [2], Ch. carnea was shown to be a complex of several cryptic species [3]. The adults feed on honeydew and pollen while the larvae are predators of a broad range of insects, e.g., aphids, mealybugs and other soft-bodied species [4,5]. Fittingly, lacewing larvae are used as efficient biological pest control agents in the field, greenhouses and orchards [5,6]. Biological pest control has received much attention through increasing insecticide resistance of several pests and legislation that aims to reduce the usage of synthetic chemical pesticides [7]. Because of their usefulness in pest control and their high resistance against many widely used pesticides, lacewings are mass-reared and marketed commercially $[5,8]$.

Endosymbionts are widely distributed in insects and often establish a long-term and stable association with their hosts. These associations may affect host fitness through various interactions, e.g., by providing essential amino acids or vitamins, reproductive manipulation, or color modifications [9-12]. Endosymbionts are not always fixed to a specific host, several endosymbionts shift host across species [13]. One of the most common endosymbionts in insects is Rickettsia spp. ( $\alpha$-Proteobacteria) with an estimated distribution in one-quarter of all terrestrial arthropod species [14]. The endosymbiont Rickettsia spp. was first described in randomly sampled arthropod host screening which also included Neuroptera [15,16]. Rickettsia spp. can also infect vertebrates, leeches, freshwater polyps, unicellular eukaryotes and plants [17-21]. Rickettsia strains that infect vertebrates, such as human pathogens, are all transmitted by arthropods and the majority of Rickettsia lineages seem to be restricted to arthropods $[15,17]$. Some of them alter host reproduction by causing male-killing (e.g., in some ladybird beetles (Coccinellidae) or jewel beetles (Buprestidae)), or parthenogenesis (e.g., in eulophid wasps) [22-25]. Rickettisa spp. are abundant in natural and laboratory insect populations, establish themselves rapidly, and remain stable at high frequencies in populations [26,27].

The role of endosymbionts in Neuroptera has so far been largely neglected. Two recent studies have described the endosymbiont Spiroplasma in the green lacewing Mallada desjardinsi with a male-killing phenotype [28,29]. Recently, a Neuroptera-specific Rickettsia screening showed that approximately $40 \%$ of the tested Neuroptera species were infected with Rickettsia, including Ch. carnea [30]. In the following sections, we will refer to the species Ch. carnea s.str. as Ch. carnea. This species was infected by strains of the $R$. bellii clade, commonly found in arthropods [15,30]. While screening Ch. carnea for endosymbionts, we also found infections with Sodalis spp., a facultative symbiont belonging to the $\gamma$-proteobacteria [31]. Sodalis was first identified in tsetse flies and later detected in different insect groups such as weevils, stinkbugs, louse flies and lice [32-36]. The prevalence of Sodalis infections can vary greatly in arthropods [37], as can the reported host-Sodalis interactions [38]. This symbiont is able to facilitate trypanosome infections in tsetse flies (Glossinidae), participate in the cuticle synthesis of weevils and modify host phenotypes [35,39]. Interestingly, a low density of Sodalis in weevils produces a host killing phenotype, whereas a high prevalence leads to a persistent and beneficial infection in the hosts [40]. 
Although green lacewings are intensively used in biocontrol applications, it is still unclear how endosymbionts are distributed on species and population level and their role in these hosts. In the present study, we screened several natural populations of Ch. carnea for Rickettsia and Sodalis infections. We also tested the similarity of infection patterns in natural and laboratory populations. To characterize the Sodalis symbiont in Ch. carnea, we assembled a draft genome from Illumina short reads for subsequent phylogenomic analysis. To study host-endosymbiont interactions, we generated Ch. carnea lines that carried Rickettsia, or Sodalis, or both, as well as endosymbiont-free lines. Based on these lines, we examined the potential impact of endosymbionts on host reproduction and the rate of vertical transmission for both symbionts in double infected lacewings. We demonstrate that the Ch. carnea/Rickettsia/Sodalis system represents a promising model for the evolution of insect-endosymbiont interactions in general.

\section{Materials and Methods}

\subsection{Endosymbiont Screening in Natural and Laboratory Ch. carnea Populations}

To compare the infection rate of endosymbionts under natural and laboratory conditions, we obtained Ch. carnea individuals from three different commercial suppliers ( $n=64$ in total) and sampled eight natural populations ( $n=84$ in total). The supplying companies were Sautter and Stepper GmbH (Ammerbuch-Altingen, Germany, 26 larvae), Biobest (Westerlo, Belgium, 18 larvae) and Katz Biotech AG (Baruth/Mark, Germany, 20 larvae). Samples from natural populations were collected in various locations in Germany and Austria between 2010 and 2015 (Table S1) and transported and stored in $70 \%$ ethanol. Species were identified based on morphology. Genomic DNA was extracted from whole insects using the NucleoSpin Tissue Kit (Marchery-Nagel, Düren, Germany) by following the manufacturer's instructions. The quality and quantity of extracted DNA were investigated using gel electrophoresis (1\% agarose gel) and a Nanophotometer P330 (Implen, Munich, Germany). To identify a Rickettsia and/or Sodalis infection, a PCR screening with species-specific $16 S$ rRNA gene primer (Table S2) was performed. Fragments of the $16 \mathrm{~S}$ rRNA gene were amplified using $2 \mu \mathrm{L}$ dNTPs, $2.5 \mu \mathrm{L}$ DreamTaq Green Buffer, $1 \mu \mathrm{L}$ of the corresponding forward and reverse $10 \mu \mathrm{M}$ primer, $12.5 \mu \mathrm{L}$ HPLC water, $0.1 \mu \mathrm{L}$ DreamTaq ${ }^{\mathrm{TM}}$ Green DNA polymerase (Thermo Fisher Scientific, Waltham, MA, USA) and $1 \mu \mathrm{L}$ of template DNA. A fragment of Rickettsia $16 \mathrm{~S}$ rRNA gene was amplified at $95^{\circ} \mathrm{C}$ for $2 \mathrm{~min}$, followed by 30 cycles of $92{ }^{\circ} \mathrm{C}$ for $30 \mathrm{~s}, 58^{\circ} \mathrm{C}$ for $30 \mathrm{~s}$ and $72{ }^{\circ} \mathrm{C}$ for $30 \mathrm{~s}$, and a final extension at $72{ }^{\circ} \mathrm{C}$ for $5 \mathrm{~min}$ [41]. A fragment of Sodalis $16 \mathrm{~S}$ rRNA gene was amplified at $95^{\circ} \mathrm{C}$ for $10 \mathrm{~min}$, followed by 35 cycles of $94{ }^{\circ} \mathrm{C}$ for $30 \mathrm{~s}, 55^{\circ} \mathrm{C}$ for $60 \mathrm{~s}$ and $72{ }^{\circ} \mathrm{C}$ for $90 \mathrm{~s}$ (according to [42] with minor adaptations). PCR amplicons were counted as positive evidence for Rickettsia or Sodalis infection. To exclude false negatives (e.g., due to low titer of the endosymbiont), the PCR product was diluted to 1:10, 1:100, and 1:1000. These dilutions were subjected to PCR again. When no bands were visible for any of the PCRs, the sample was counted as not infected. We included in each run per primer pair a negative control containing all PCR ingredients except for the DNA, and a positive control containing a DNA sample that was previously tested positive.

\subsection{Molecular Characterization of Endosymbionts}

We used a whole-genome shotgun approach to generate a metagenome assembly containing host and endosymbiont contigs for data mining. For this purpose, a double-indexed Illumina library was constructed from the DNA of a co-infected 2nd instar green lacewing larva as detailed in Meyer and Kircher [43] and Kircher et al. [44]. The insect sample was obtained from the company Sautter and Stepper GmbH (Ammerbuch-Altingen, Germany) and DNA extracted using the DNeasy ${ }^{\circledR}$ Blood and Tissue Kit (Qiagen, Venlo, The Netherlands) following the supplier's instruction. The quality of the extracted DNA was tested with a Nanophotometer and gel electrophoresis (1\% agarose). The library was then sequenced as 140-bp paired-end run on an Illumina HighSeq 2500 (Illumina, San Diego, CA, USA) at the Max Planck Institute for Evolutionary Anthropology (Leipzig, Germany). 
Base-calling was performed with freelbis [45], adapters were trimmed and reads with more than five bases below a quality threshold of 15 were discarded. A meta-assembly was created using IDBA-UD [46], with k-mers 21-81 in steps of ten. Markers for qPCR and molecular characterization of endosymbionts were recovered using BLAST-searches against the assembled contigs. Raw reads have been submitted to NCBI Genbank under the accessions PRJNA506348. The assembly is available under https://doi.org/10.5281/zenodo.2163010. Rickettsia endosymbionts of green lacewings were already phylogenetically characterized in Gerth et al. [30]. For the molecular characterization of the Sodalis strain, assembled contigs were blasted with BLASTN against NCBI GenBank. All recovered Sodalis contigs were used as reference for subsequent mapping using NextGenMap 0.4.12 [47] to retrieve all putative Sodalis reads. The coverage of all Sodalis contigs was evaluated with qualimap 2.2.1 [48] and retrieved reads were newly assembled with SPAdes 3.1.1 [49], an assembler optimized for bacterial and archaeal genomes, to generate a Sodalis draft genome. For the phylogenetic placement of the lacewing Sodalis strain, we recovered the $16 S$ rRNA gene using BLAST search and compiled a Sodalis reference dataset based on a recent study by Sochova et al. [38]. A list of sequences included in the analysis can be found in Table S3.

The alignment was conducted using MAFFT [50]. We used GUIDANCE2 [51] for alignment masking, where we chose to generate alternative guide trees from 100 bootstrap replicates. After the removal of unreliable columns, we additionally removed all columns containing more than $20 \%$ gaps. For phylogenetic analyses, we conducted model testing and a Maximum Likelihood analysis with 1000 bootstrap replicates using IQ-TREE version 1.4.2 [52]. The selected model was the TIM3 + I + G model, with the three rate categories.

\subsection{Endosymbiont-Host Interaction}

\subsubsection{Insect Rearing}

Total developmental time was approximately 70 days from eggs to adults in Ch. carnea under our laboratory conditions. Insect cultivation and all experiments were carried out under controlled environmental conditions in a climate cabinet (Percival Scientific, Perry, IA, USA) with a constant temperature of $22^{\circ} \mathrm{C} \pm 2{ }^{\circ} \mathrm{C}$, a $16 \mathrm{~h}$ light and $8 \mathrm{~h}$ dark cycle, and relative humidity of $65 \pm 5 \%$. We started a Ch. carnea culture with 85 second instar larvae obtained from the company Sautter and Stepper $\mathrm{GmbH}$ (Ammerbuch-Altingen, Germany). All larvae were reared individually in small round plastic containers ( $3 \mathrm{~cm}$ diameter) and fed with dead moth eggs (Sitotroga sp., Katz Biotech, Baruth/Mark, Germany) twice a week. Water droplets were added to the container wall three times a week. To exclude contaminations from the diet, Sitotroga eggs were PCR screened for Rickettsia and Sodalis infections, which were not detectable in the diet. At the 3rd instar, a small piece of corrugated cardboard was added to each container to facilitate pupation. After eclosion, adult lacewings were fed with a mixture of honey, water, yeast extract, and sucrose (1:1:1:1) every other day. Adults aged 7 days were then mated by putting $2-4$ females and $2-4$ males in one cage $(38 \times 38 \times 60 \mathrm{~cm})$. After 5 days, females were separated into a plastic container $\left(\sim 38 \mathrm{~cm}^{3}\right)$, covered with a fine cotton mesh to encourage oviposition and fed every other day with the food mixture as previously described. The mesh containing eggs was changed every 5 days and stored in a small petri dish $(6 \times 1.5 \mathrm{~cm})$. These dishes were checked daily and hatched larvae were collected and reared separately to reduce the rates of cannibalism. After eggs were collected, all mothers were screened via PCR for the presence of Sodalis and Rickettsia as previously described. This approach allowed us to establish lines of lacewings that were either (1) symbiont free, (2) infected with Rickettsia only, (3) infected with Sodalis only or (4) infected with both Rickettsia and Sodalis. All further experiments were performed after amplifying the lines for two generations.

\subsubsection{Vertical Transmission Rate of Endosymbionts in Ch. carnea}

Vertical transmission rates of both endosymbionts were studied in $14 \mathrm{Ch}$. carnea females with a combined infection of Rickettsia and Sodalis. For this purpose, females were mated with males 
carrying Rickettsia and Sodalis and reared as previously described. After 16 days the females were removed and PCR screened for Rickettsia and Sodalis symbionts as described above. Offspring were collected every day and allowed to develop for 28 days (until 3rd instar), before being collected and PCR screened for the symbionts. This was done for practical reasons, as it is difficult to reliably extract DNA from single individuals in earlier stages. The rate of vertical transmission was determined by calculating the number of infected offspring divided by the number of total offspring tested per female. Based on the low number of single Rickettsia and Sodalis infected individuals in the ordered larvae, we were not able to get a representative number of replicates for these three lines to study vertical transmission in single infected green lacewings.

\subsubsection{Effect of Endosymbionts on Host Reproductive Success}

The endosymbiont effect on host reproductive success was studied in 30 female lacewings, of which 7 were infected with Rickettsia only, 8 with Sodalis only, 10 with Rickettsia and Sodalis and 5 were without any of these symbionts. Rickettsia, Sodalis, and co-infected females were mated with males of the same infection status. In combined endosymbiont pairs, 4 males were singly infected with Sodalis. Females without symbionts were mated with Rickettsia or Rickettsia and Sodalis infected males to control for endosymbiont-mediated sex bias. Non-conformities in the infection stages of the males were based on endosymbiont screening after mating. After a mating period of five days, adults were separated and females were placed individually in round plastic containers. We counted the number of eggs per female every five days for 45 days in total and transferred all eggs from one female into a small petri dish. After these 45 days, the mothers were killed and screened for symbionts by PCR as described above. Starting from the day the first eggs were collected, we visually inspected the Petri dishes for hatched larvae. The larvae were counted visually every day until all eggs were empty or dried out. All larvae were then kept separately in small cups and fed with dead Sitotroga eggs until they pupated. The number of pupae and emerged adults were counted every day (Table S4). Finally, using a general linear model with a quasi-Poisson distribution with the standard commands in R [53], we compared the reproductive success for the category "number of eggs" among the four different endosymbiont lines. We used the same statistical model for the categories, "larvae", "pupae" and "emerged adults".

\subsubsection{Endosymbiont Titer in Single and Co-Infected Ch. carnea}

To determine symbiont titers in single and co-infected green lacewings, we used a qPCR approach. To this end, we collected 26 adult females (9 with Rickettsia only, 9 with Sodalis only, 8 with Rickettsia and Sodalis). All of them were unmated and of similar age ( 14 days). In addition, we tested Rickettsia and Sodalis titer in 10 co-infected larvae. Due to the low percentage of single infected individuals, we were unable to collect a representative number of only Rickettsia or Sodalis infected larvae. Genomic DNA was extracted using the NucleoSpin Tissue Kit protocol as previously described. Quantification of Rickettsia and Sodalis was examined by amplification of a $222 \mathrm{bp}$ fragment of gltA for Rickettsia and a $182 \mathrm{bp}$ fragment of groEL for Sodalis, respectively. To design Rickettsia and Sodalis specific primers, we used a published R. bellii gltA sequence for Rickettsia, which was available in NCBI (accession number DQ146481.1) and for Sodalis a groEL sequence of the closely related S. praecaptious (accession number JX444566.1). Both sequences were blasted with BLASTN against our whole-genome shotgun assembly (see above) and the corresponding contigs were aligned with MAFFT version 7 [50]. Primers for these fragments were designed using Primer3 v. 0.4.0 (Table S2, [54]). Primer efficiency was tested using a 1:10 dilution series of DNA from pooled co-infected Ch. carnea adults. The calculated efficiency was similar for all qPCR primers (105-106\%). To normalize to host size, we amplified a fragment of the host insect gene actin, using primers from Liu et al. [55]. Actin was tested for an almost constant Ct value between treatments by screening 30 Rickettsia, Sodalis or Rickettsia and Sodalis infected Ch. carnea (STD \pm 0.5 cycles).

All qPCR reactions were performed in $10 \mu \mathrm{L}$ volumes on a PikoReal Real-time PCR System (Thermo Fisher Scientific, Waltham, MA, USA) using $5 \mu \mathrm{L}$ Maxima SYBR ${ }^{\circledR}$ Green qPCR Master Mix 
(2X, Thermo Fisher Scientific, Waltham, MA, USA), $2.5 \mu \mathrm{mol}$ of forward and reverse primer and $500 \mathrm{ng}$ DNA. The qPCR program was set as follows: initial incubation at $95^{\circ} \mathrm{C}$ for $1 \mathrm{~min}$, followed by 40 cycles at $95{ }^{\circ} \mathrm{C}$ for $15 \mathrm{~s}, 55^{\circ} \mathrm{C}$ for $15 \mathrm{~s}$, and $72{ }^{\circ} \mathrm{C}$ for $45 \mathrm{~s}$, followed by a $0.2{ }^{\circ} \mathrm{C}$ increment melt curve from 60 to $95^{\circ} \mathrm{C}$. After PCR amplification, a melt curve analysis was conducted using the PikoReal Software (Thermo Scientific, Waltham, MA, USA) to confirm that there was one amplified product. Individual samples were run in duplicates. A no-template control and negative control for both endosymbiont primer sets were run on each plate. The negative control contained DNA of Ch. carnea only infected with the endosymbiont where the primer was not designed for, for example, we used the DNA of an only Sodalis infected Ch. carnea individual for the primer set of gltA (Rickettsia). The negative controls and the no-template controls did not show amplification for any of the genes tested.

To compare endosymbiont density in single and co-infected adults and co-infected larvae, we used gene copies as a proxy for symbiont number in relation to copies of a host gene as a normalization of host size. This was done by calculating the $2^{\Delta \mathrm{Ct}}$ values using the $\mathrm{Ct}$ value of the corresponding endosymbiont and host gene. We refer to this value in our manuscript titer. Differences between groups were determined using a one-way ANOVA with Tukey post-hoc test in R [53]. For statistical analysis, the calculated values of all genes were normalized by using a log transformation (Table S5).

\section{Results}

\subsection{The Screening of Rickettsia and Sodalis Symbionts on Population Levels in Natural and Laboratory Ch. carnea}

To compare distribution patterns of endosymbionts in Ch. carnea in natural and laboratory populations, we screened 148 individuals representing eight natural and three commercially propagated populations. Rickettsia infections were found in all-natural populations; in total, $64 \%$ of the individuals were infected (33-92\% infected individuals/population, Figure 1). In commercial laboratory populations, Rickettsia was found in 67\% of all screened individuals (25-94\% infected individuals/population), $12 \%$ of these as single infections and $88 \%$ as co-infections with Sodalis. The endosymbiont Sodalis was only detected in laboratory $\mathrm{Ch}$. carnea where $83 \%$ of screened individuals were infected (70-94\% infected individuals/population), $28 \%$ of these as single infections and $72 \%$ as co-infections with Rickettsia (Figure 1).
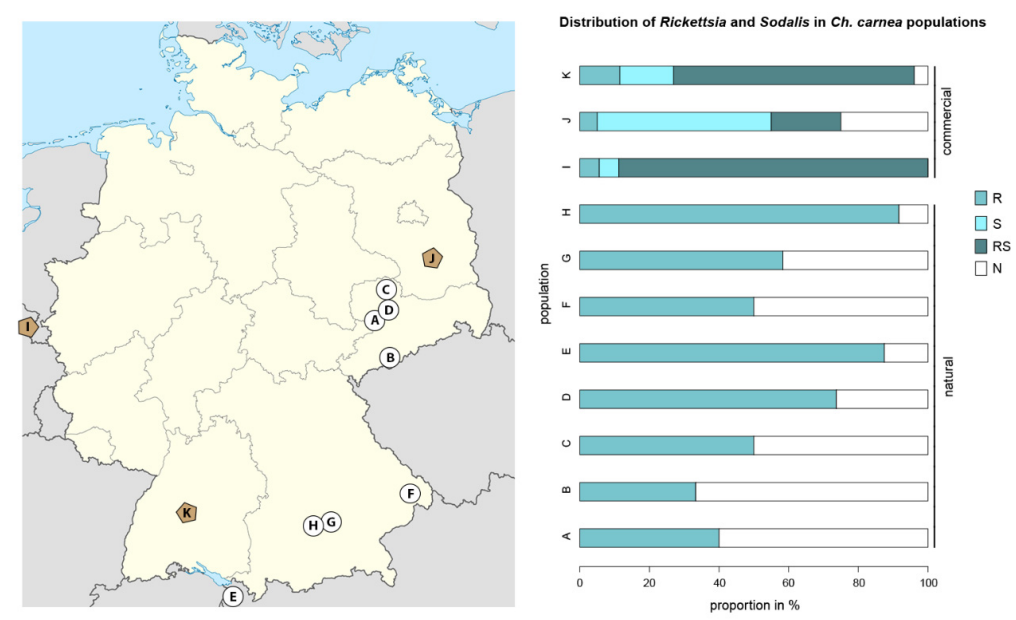

Figure 1. Distribution of Rickettsia and Sodalis symbionts in Chrysoperla carnea s. str. in natural populations (Saxony and Bavaria, Germany and Austria; map: white circle) and commercially reared populations (map: dark rhombus indicates the location of the company headquarters, not the origin of populations). R: Rickettsia infected, S: Sodalis infected, RS: Rickettsia and Sodalis infected, N: uninfected. Letters in the map highlight collection/rearing sites. A: Trages, B: Neudorf, C: Dahlen, D: Püchau, E: Rankweil, F: Schönberg, G: Wippenhausen, H: Kranzberg, I: Biobest, J: Katz Biotech, K: Sautter and Stepper. 


\subsection{Molecular Phylogenetic Characterization of Endosymbionts}

Previous phylogenetic analysis demonstrated that the Rickettsia strain that infected Ch. carnea belonged to the Rickettsia bellii clade [30]. For the Sodalis strain in Ch. carnea, 4,289,304 reads could be used to assemble a draft genome, which was represented by 558 contigs with an N50 of 20,104 b and a coverage of $\sim 67 \mathrm{x}$. Based on this draft, the genome of the Sodalis endosymbiont was around $4.3 \mathrm{Mbp}$ in size.

For the phylogenetic placement using the 16S rRNA gene, our analyses found the green lacewing Sodalis strain nested within a strongly supported monophyletic group of Sodalis endosymbionts (Figure 2). This clade contains mostly symbiotic bacteria isolated from insect hosts, but also Sodalis praecaptivus isolated from human wound tissue. The Ch. carnea infecting strain was found in a rather basally branching position, branching between some lineages isolated from beetle taxa, but not forming a clade with them. Altogether, the ingroup topology of Sodalis was not well supported and partly not resolved.

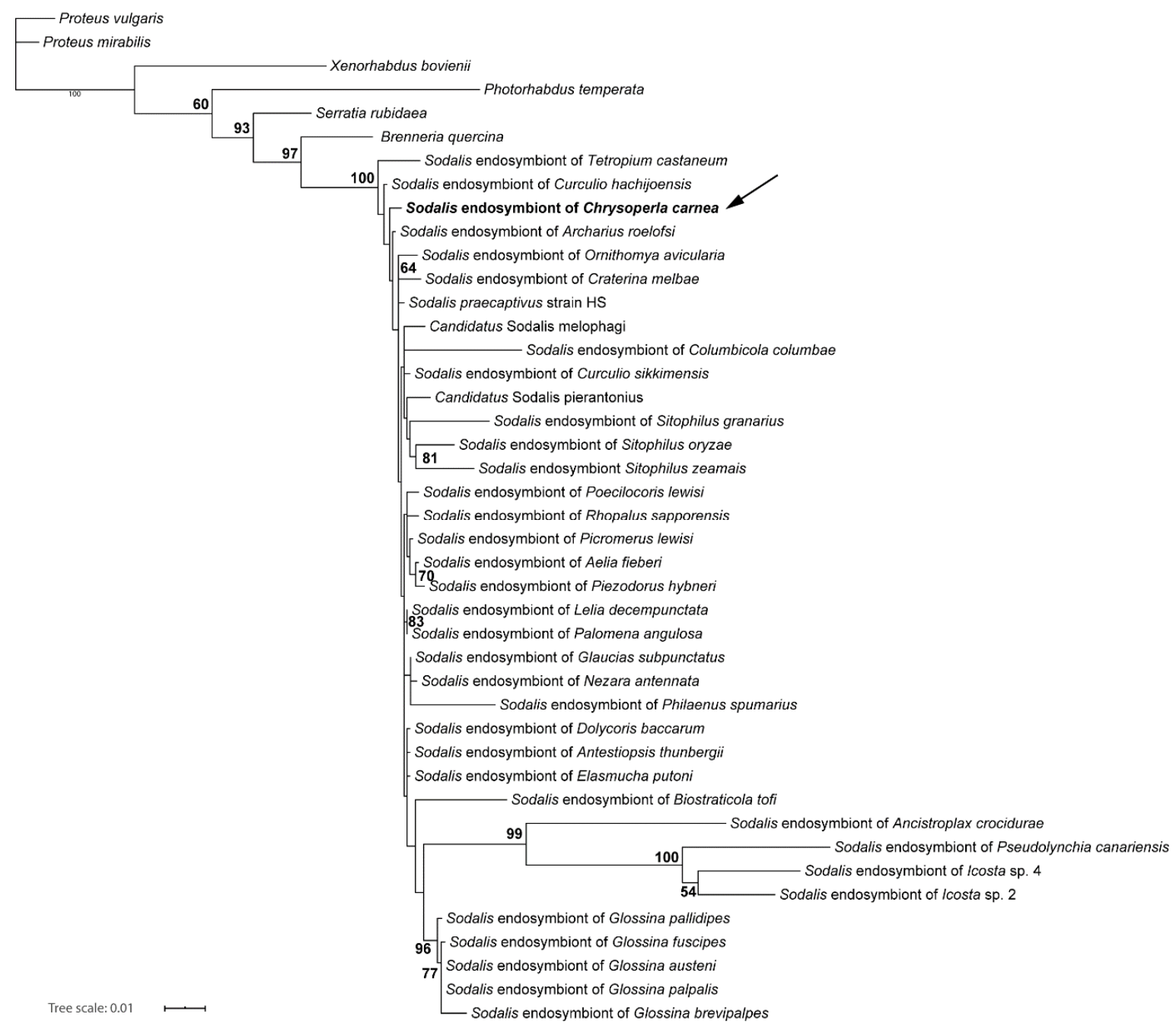

Figure 2. Phylogenetic analysis of the $16 \mathrm{~S}$ rRNA gene dataset of Sodalis strains using Maximum Likelihood under the TIM3 + I + G model as implemented in IQ-TREE. Bootstrap support from 1000 pseudoreplicates is given at the nodes. Only support values higher than $50 \%$ are displayed.

\subsection{Endosymbiont Host Interaction}

The rate of vertical transmission estimated from the number of infected offspring divided by the number of total offspring was overall very high for both endosymbionts ( $>89 \%)$. However, Sodalis was 
vertically transmitted at a slightly higher rate (97\%) than Rickettsia $(89 \%)$ in co-infected lacewings (Table 1).

Table 1. Number and percentage of offspring infected with Rickettsia and/or Sodalis symbionts from 13 double infected Chrysoperla carnea s. str. females (in total 104 individuals were tested).

\begin{tabular}{ccc}
\hline & Rickettsia & Sodalis \\
\hline Number of offspring infected with only one endosymbiont & $3(2.9 \%)$ & $11(10.6 \%)$ \\
\hline Number of offspring infected with both endosymbionts & $90(86.5 \%)$ & $90(86.5 \%)$ \\
\hline Total number of infected offspring & $93(89.4 \%)$ & $101(97.1 \%)$ \\
\hline
\end{tabular}

Reproductive success differed considerably between groups. We found a reduced reproductive output in single Sodalis infected Ch. carnea in comparison to uninfected lacewings in all life stages (Figure 3, Table 2). Single Rickettsia infected Ch. carnea performed similarly as uninfected lacewings. Lacewings with co-infections of Rickettsia and Sodalis showed a reduced reproductive output similar to single Sodalis infections. In general, the number of hatched larvae was rather low, which might indicate that our rearing conditions were sub-optimal (Figure 3, Table S4).

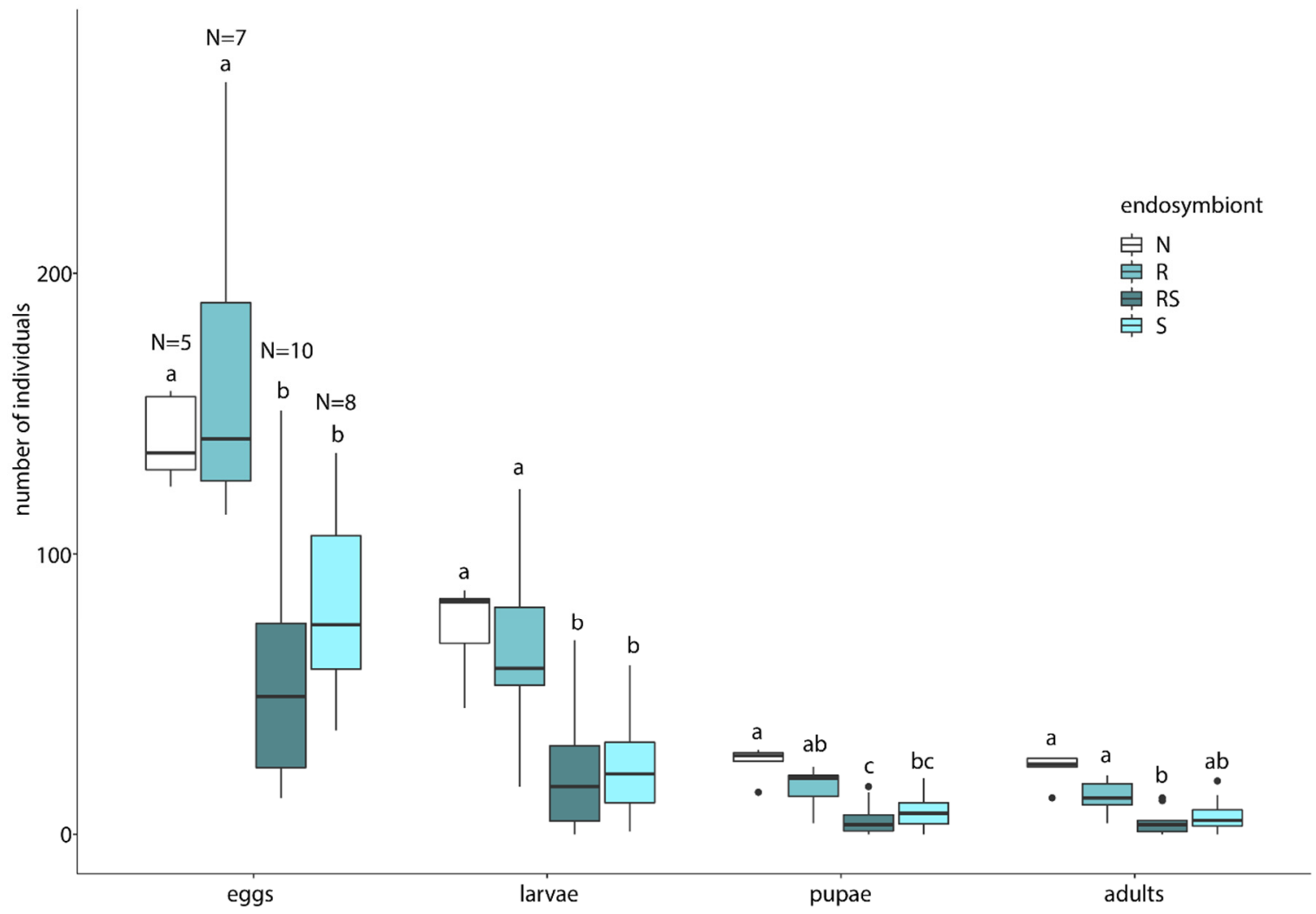

Figure 3. Number of eggs, larvae, pupae and adults of Chrysoperla carnea s. str. lines differing in levels of endosymbiont infections. N: non-infected, R: only Rickettsia, S: only Sodalis or RS: co-infected with Rickettsia and Sodalis. Values are presented as boxplot and the box is defined by the 25th and 75th percentiles (lower and upper quartile). The thick horizontal line is the median and the vertical lines (whiskers) have maximum a distance of 1.5 times the percentiles length. Dots outside the line can be considered as outliers. Different letters indicate $p$-values $<0.05$ based on general linear model, $n=$ number of females. 
Table 2. Statistical comparison of laid eggs, viable larvae, number of pupae and emerged adults of Chrysoperla carnea s.str. lines of different endosymbiont infections, using a general linear model with a quasi-Poisson distribution. $n$ : no endosymbiont, R: only Rickettsia, S: only Sodalis, RS: Rickettsia and Sodalis infected. $p$-value ${ }^{*}<0.05 ;{ }^{* *}<0.01 ;{ }^{* * *}<0.001$.

\begin{tabular}{cccccccc}
\hline & & R-N & RS-N & S-N & R-RS & R-S & RS-S \\
\hline \multirow{2}{*}{ Eggs } & $\mathrm{t}$ & 0.678 & -3.066 & -2.063 & -3.739 & -2.730 & 0.90 \\
& $p$-value & 0.504 & $0.005^{* *}$ & $0.049^{*}$ & $0.001^{* *}$ & $0.012^{*}$ & 0.382 \\
\hline \multirow{2}{*}{ Larvae } & $\mathrm{t}$ & -0.327 & -3.212 & -2.941 & -2.877 & -2.614 & 0.069 \\
& $p$-value & 0.747 & $0.004^{* *}$ & $0.007^{* *}$ & $0.009^{* *}$ & $0.016^{*}$ & 0.945 \\
\hline \multirow{2}{*}{ Pupae } & $\mathrm{t}$ & -1.502 & -4.276 & -3.340 & -2.856 & -1.914 & 0.868 \\
& $p$-value & 0.145 & $<0.001^{* * *}$ & $0.003^{* *}$ & $0.009^{* *}$ & 0.070 & 0.398 \\
\hline \multirow{2}{*}{ Adults } & $\mathrm{t}$ & -1.864 & -4.518 & -3.606 & -2.809 & -1.863 & 0.883 \\
& $p$-value & 0.074 & $<0.001^{* * *}$ & $0.001^{* *}$ & $0.010^{*}$ & 0.080 & 0.390 \\
\hline
\end{tabular}

Finally, by using qPCR we found that the Rickettsia titers were similar between single and co-infected adult individuals of Ch. carnea (Figure 4). Larvae-adult comparison of Rickettsia titer in co-infections significantly differed, with the larvae having a lower titer (Figure 4, Table 3). Sodalis titers differed significantly in single and co-infected adults. Co-infected adults with Rickettsia had a distinctly higher Sodalis titer than single infected ones. The Sodalis titer was also reduced in co-infected larvae compared to co-infected adults.
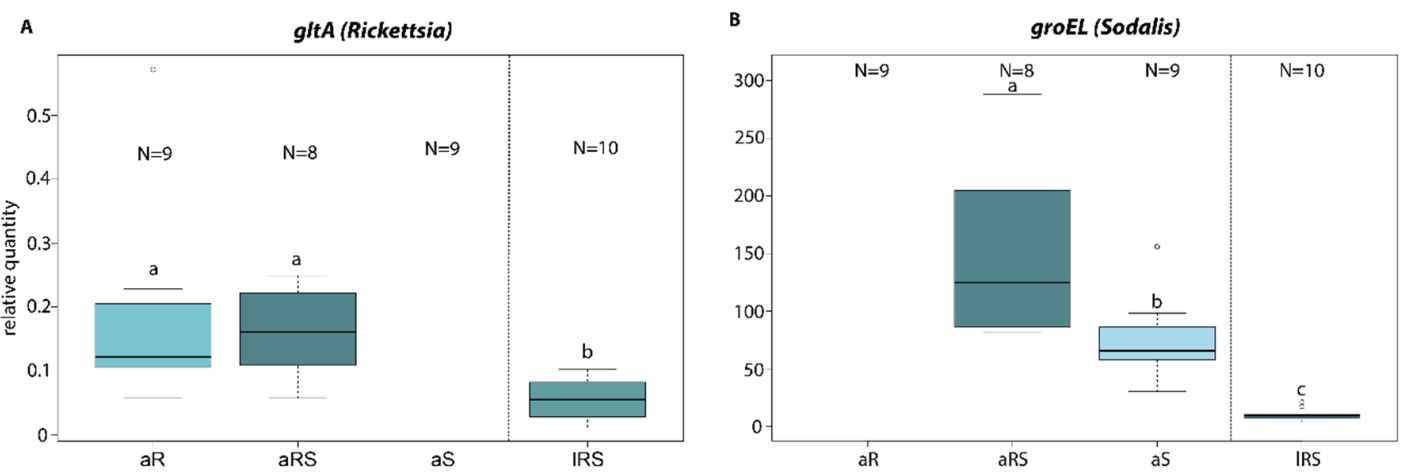

Figure 4. Relative quantity of Rickettsia and Sodalis endosymbionts in Chrysoperla carnea s. str. using Rickettsia specific (gltA) (A) or Sodalis specific (groEL) gene fragments (B). Ch. carnea were infected with only Rickettsia or Sodalis or co-infected. a: adult; l: larvae; S: Sodalis infection only; R: Rickettsia infection only; RS: co-infection with Rickettsia and Sodalis; Values are presented as boxplot and the box is defined by the 25 th and 75 th percentiles (lower and upper quartile). The thick horizontal line is the median and the vertical lines (whiskers) have maximum a distance of 1.5 times the percentiles length. Dots outside the line can be considered as outliers. Different letters indicate significant differences between groups using one-way ANOVA, $p$-value $<0.05$.

Table 3. Statistical results of the relative quantity of Rickettsia (gltA) and Sodalis (groEL) in adult Chrysoperla carnea s. str. with Rickettsia only (aR), Sodalis only (aS) or Rickettsia and Sodalis (aRS) infections and in co-infected larvae (IRS) using a one-way ANOVA and Tukey post-hoc test. $p$-value * $<0.05$, $* *<0.01, * * * 0.001$.

\begin{tabular}{cccc}
\hline Test & Lines & gltA(Rickettsia) & groEL (Sodalis) \\
\hline ANOVA & & $\begin{array}{c}\mathrm{F}_{(2 / 24)}=9.744 \\
p<0.001^{* * *}\end{array}$ & $\begin{array}{c}\mathrm{F}_{(2 / 24)}=146.18 \\
p<0.001^{* * *}\end{array}$ \\
\hline \multirow{2}{*}{ Tukey post-hoc } & aS-aRS & - & $p=0.021^{*}$ \\
& aR-aRS & $p=0.997$ & - \\
& lRS-aRS & $p=0.002^{* *}$ & $p<0.001^{* * *}$ \\
\hline
\end{tabular}




\section{Discussion}

\subsection{Endosymbiont Screening on Population Levels in Natural and Laboratory Ch. carnea}

Our analysis showed that both Rickettsia and Sodalis were common endosymbionts in Ch. carnea populations. This is the first record of Sodalis sp. found in Neuroptera. However, the most common endosymbiont was Rickettsia, which occurred in all tested natural and laboratory populations. Our screening of Rickettsia infections revealed infection rates ranging from $25 \%$ to $94 \%$ in both population types (laboratory and natural). The highly variable infection rates between populations are typical for Rickettsia infections in insects. For instance, wild whitefly (Bemisia tabaci, Hemimptera: Aleyrodidae) populations showed a very broad range in Rickettsia infection frequency (22\% to $100 \%)$. In Buprestidae (Coleoptera) approximately half of the tested individuals were infected (46.3\%) and in the mirid bug species Nesidiocoris tenuis (Heteroptera: Miridae) nearly all individuals were infected $(93 \%$ to $100 \%)[23,41,56]$.

While screening green lacewings for endosymbionts using a metagenomic approach, we also detected Sodalis, a well-known $\gamma$-proteobacterial endosymbiont of tsetse flies [57]. This symbiont was also found in several other insects, such as stinkbugs, spittlebugs, bird lice, hippoboscid flies, weevils, psyllids or scale insects. [36,37,58]. Although we detected a high frequency of Sodalis symbionts in Ch. carnea in all laboratory populations, none was found in natural ones (Figure 1). Differences in the presence of Sodalis in commercially available specimens and naturally collected specimens were also noticed by Saeed and White in bees [59]. They observed Sodalis in only 3 out of 100 individual bees captured in the wild and in 10 out of 85 individuals when sampling commercially reared individuals. Variations in endosymbiont infection rates in natural and laboratory populations seem to be host species-specific. While Wolbachia infection rates were similar in natural and laboratory Drosophila melanogaster (Diptera) populations [60], this was not true for tsetse flies. The same Wolbachia supergroup had highly variable infection rates in natural populations, whereas $100 \%$ of the individuals were infected in laboratory populations of the tsetse fly Glossina morsitans morsitans [61].

The complete absence of Sodalis in natural Ch. carnea populations is potentially caused by differences in selection pressures between laboratory and natural populations. In natural populations, lacewings are subject to fluctuating environmental conditions, natural enemies and competition for nutrition with other arthropods. Conceivably, these additional sources of stress are more relaxed or missing under laboratory conditions, which may be favorable for Sodalis. In line with this, our data suggest that Sodalis infections cause fitness costs in Ch. carnea. Based on the fitness effects, Sodalis may be eliminated faster in natural than in laboratory populations, where inbreeding and stable conditions may enhance the transmission rate of endosymbionts. For instance, temperature varies greatly under natural conditions, whereas laboratory populations are generally reared at a constant and relatively high temperature to optimize breeding success. A correlation of temperature with the rate of transmission has been reported for several bacteria [62,63]. A higher Sodalis infection frequency was detected in weevils living at localities with higher temperatures [64]. It is also conceivable that Sodalis reinfections from the environment occur more frequently in laboratory populations. A further reason for the absence of Sodalis in natural populations might be our sampling design. Due to the low number of sampled individuals per population and our focus on two regions (Saxony and Bavaria/Austria), we might have missed Sodalis in case of a low prevalence in the population. A low prevalence of Sodalis in natural populations of insect hosts has been described from stinkbug populations (7.5\%) [37]. If individuals from such $\mathrm{Ch}$. carnea populations were sampled for commercial breeding and based on the efficient vertical transmission of this symbiont, we would find a high Sodalis frequency in commercial populations as our data showed. However, given the current state of knowledge, it can only be speculated why Sodalis is only present in laboratory populations of the tested green lacewings. 


\subsection{Molecular Phylogenetic Characterization of Endosymbionts}

Both Rickettsia and Sodalis symbionts occur in many diverse arthropod orders and often different strains infect different hosts. [15,37,38,57]. Rickettsia is subdivided into 13 lineages. In general, they do not co-speciate with their hosts, however, a host shift takes place more frequently between related arthropods [15]. A study that investigated Rickettsia strains in the insect order Neuroptera, to which our host insect belongs, found also a more host-specific distribution of diverse Rickettsia lineages in this insect order [30]. Our finding supported this prediction. We found the same strain (R. bellii group) in the here investigated green lacewings as Gerth et al. [30] already reported for different populations of Ch. carnea.

To classify the Sodalis symbiont of Ch. carnea also in terms of their evolution, this endosymbiont was characterized genetically. Our phylogenetic analysis showed that this strain is closely related to published Sodalis strains. Several other close relatives of this species have already been identified in different insect hosts, such as Coleopetera or Heteroptera $[65,66]$. Whereas almost all other known Sodalis strains have been described as primary or secondary endosymbionts of insects, we also recovered Sodalis praecaptivus nested between these strains. S. praecaptious was isolated from a human wound as a result of an accident with a tree branch [67]. The $S$. praecaptivus strain is regarded as a free-living member of Sodalis. Its genome is $5.17 \mathrm{Mbp}$, the largest of all sequenced Sodalis strains so far [68]. With $4.3 \mathrm{Mbp}$, the draft genome of the Sodalis strain in green lacewings is comparable in size to those of Candidatus S. pierantonius (4.5 Mbp), a secondary endosymbiont of the rice weevil [69], and S. glossinidius (4.2 Mbp), a secondary endosymbiont of the tsetse fly [70]. The Sodalis-like primary endosymbiont of the spittlebug Philaenus spumarius has $1.39 \mathrm{Mbp}$, the smallest genome of all known strains [58,71]. It has been hypothesized that Sodalis strains adapted independently to an endosymbiotic lifestyle with different insect hosts, resulting in a reduction of genome size and complexity [69,72]. The genome size of the different strains seems to correlate with the level of dependency to their hosts. However, a more contiguous assembly of the green lacewing Sodalis strain is necessary for a detailed analysis of the state of its "genome degeneration".

\subsection{Endosymbiont Host Interaction}

Based on the high infection rate in several Ch. carnea populations, the vertical transmission rate of both endosymbionts was studied in co-infected green lacewings. When sharing the same host, endosymbionts have to compete for nutrients and space either by sharing resources or evolving different niches, e.g., inhabit special cells or organs [73,74]. This phenomenon was found in tsetse flies, where Wolbachia only infects oocytes, Wigglesworthia bacteriocytes and milk glands, and Sodalis several organs [75]. However, our data show that also in co-infections, Rickettsia and Sodalis transmission rates are very high in green lacewings (89-97\%, Table 1). The Rickettsia transmission rate is consistent with an earlier study in whiteflies under laboratory conditions [26]. Slightly lower rates were found in studies of tsetse flies (Glossina morsitans) for Sodalis, $(67-75 \%$, [39,76]). However, it has to be considered that the tsetse flies were infected with another Sodalis strain than the green lacewings. Whether both Rickettsia and Sodalis share the same host cells in green lacewings or they are spatially separated remains to be explored.

Negative fitness impacts are a prevalent phenomenon associated with endosymbionts [10]. Therefore, we studied the effects of Rickettsia and/or Sodalis on their host reproductive success in Ch. carnea. In the present study, we found no effect of single Rickettsia infections on the reproductive success of its host (Figure 3). In general, Rickettsia spp. are able to manipulate insect fitness in both negative or positive ways. While negatively affecting body weight, fecundity and longevity in aphids [77,78], a positive effect was found on body size, number of offspring, development and survival rate in whiteflies and leeches $[19,26]$. In the present study Sodalis seems to have a detrimental effect on the number of viable offspring in Ch. carnea. Starting with a lower amount of laid eggs, the number of larvae, pupae and eclosed adults were also reduced compared to endosymbiont free breeding lines. This impact on fecundity and pupal emergence rate was not found in tsetse flies. 
In these hosts, Sodalis established trypanosome infections and longevity $[39,79,80]$. However, it has to be considered that tsetse flies were infected with the strain S. glossinidius. The effect of Sodalis on other insects is less well understood. Detrimental effects on host fitness were also reported from other endosymbionts. The endosymbiont Regiella spp. inhibited the formation of winged aphids in the grain aphids Sitobion avenae, depending on the temperature [81]. It might be that the detrimental effect of Sodalis in Ch. carena also occurs only under certain environmental conditions. The generally low larval hatching rates in our study may indicate sub-optimal rearing conditions. This possibly leads to the fact that our results do not occur under more optimal conditions. Carrying an endosymbiont is often accompanied by a trade-off for the host. A meta-study about endosymbionts in aphids demonstrated that endosymbionts are often associated with costs for the hosts, such as increased developmental time, reduced longevity and fecundity. On the other hand, hosts often benefit from resistance against parasitic wasps [82]. It is conceivable that we missed the beneficial effects of Sodalis infections in Ch. carnea. The co-occurrence of Rickettsia and Sodalis found in Ch. carnea was also reported in weevils and lice $[64,83]$. In our study, co-infections showed a detrimental effect on reproductive success, similar to single Sodalis infections. To test, whether endosymbiont density is constant in single and co-infected green lacewings, Rickettsia and Sodalis titers were measured in both infection lines (single and co-infected). We found an asymmetrical interaction between the co-infected symbionts. Rickettsia density was not affected by co-infections with Sodalis endosymbionts in adult green lacewings. This indicates that even both symbionts are carried by the same host, they might have occupied different niches to avoid competition about available nutrients and space. For example, in the whitefly Bemisia tabaci Rickettsia was found throughout the whole host body and other endosymbionts (Hamiltonella, Wolbachia and Cardinum) were only localized in bacteriocytes [84]. Other studies showed that Rickettsia can also be localized in specific host tissues [78]. Whether Rickettsia is evenly distributed or localized on specific tissue in Ch. carnea has to be studied. Interestingly, we observed a contrasting interaction between single and co-infections of Sodalis in Ch. carnea, where single infections showed a lower density than in the presence of Rickettsia (Figure 4) These findings suggest that Sodalis might benefit from the presence of Rickettsia, even though we found no enhanced phenotypic effect on the reproductive success in co-infected $\mathrm{Ch}$. carnea.

During the lifetime of $\mathrm{Ch}$. carnea the density of both endosymbionts was not constant in co-infected individuals. We found a lower Sodalis and Rickettsia density in larvae than in adults. Variations of endosymbiont density during the life cycle of insects is not uncommon. Sodalis infections were also not detected in all host life stages of the cereal weevils (Sitophilus, Coleoptera) where they probably are involved in cuticle synthesis in young adults, after which the endosymbiont was eliminated [35]. The density of other endosymbionts also varies during the lifetime of insect hosts. For instance, the endosymbiont Spiroplasma in Drosophila melanogaster was reduced in the larval stage [74]. Reasons for the low density of both endosymbionts in Ch. carnea larvae might be influenced by using different diet sources in different life stages (insects vs. honeydew and pollen), different environments (living exclusively on a plant vs. flying around plants), larval-specific developmental factors (e.g., moulting) or changes in the host immune system between both life stages. Therefore, further investigation is required, especially regarding the relevance of the symbionts and their function in several life stages.

\section{Conclusions}

This work is a first step in studying the distribution and fitness impact of endosymbionts in the common green lacewing Ch. carnea, a species frequently used in biological pest control. Based on our results, we generated new hypotheses about underlying mechanisms and functions of this specific symbiont-host interaction. The negative fitness effect of Sodalis found in this study may have an important impact on commercial rearing and it should be explored if treating Ch. carnea with antibiotics may improve the rearing success and efficiency.

Supplementary Materials: The following materials are available online at http://www.mdpi.com/2075-4450/11/12/ 867/s1, Table S1: Collection data and endosymbiont infections of natural Chrysoperla carnea populations, Table S2: 
PCR and qPCR primer, Table S3: Accession numbers of sequences used for the phylogenetic placement of the green lacewing Sodalis strain, Table S4: Experimental data of reproduction effect experiment, Table S5: Relative quantity of Rickettsia and Sodalis endosymbionts in Chrysoperla carnea.

Author Contributions: Conceptualization, R.S., M.G., M.S. and C.B.; Formal analysis, R.S. and C.B.; Funding acquisition, C.B.; Investigation, R.S. Methodology, R.S., M.G., S.R., A.G. and C.B.; Project administration, C.B.; Resources, N.M.v.D.; Software, R.S., M.G. and C.B.; Supervision, M.G. and C.B.; Visualization, R.S. and C.B.; Writing—original draft, R.S., M.G. and C.B.; Writing—review and editing, S.R., A.G., M.S. and N.M.v.D. The project was designed by C.B., M.G. and R.S.; A.G., C.B. and M.G. collected and identified insects in Saxony and Bavaria. All authors have read and agreed to the published version of the manuscript.

Funding: This research was funded by a flexpool grant of the German Centre for Integrative Biodiversity Research (iDiv) funded by the German Research Foundation (DFG-FZT 118, 202548816).

Acknowledgments: We thank Katharina Grosser for her support in cultivation, Christian Ristok for helpful com-ments on statistics and Anne Weigert for laboratory assistance. Felix Wäckers of BioBest is thanked for providing Ch. carnea. We acknowledge support by the Open Access Publication Funds of the Göttingen University. The authors thank three anonymous reviewers for critically reading and advises on an earlier version of the manuscript.

Conflicts of Interest: The authors declare no conflict of interest. The funders had no role in the design of the study; in the collection, analyses, or interpretation of data; in the writing of the manuscript, or in the decision to publish the results.

\section{References}

1. Aspöck, U. Phylogeny of the neuropterida (insecta: Holometabola). Zool. Scr. 2002, 31, 51-55. [CrossRef]

2. Henry, C.S. Sibling species, call differences, and speciation in green lacewings (neuroptera: Chrysopidae: Chrysoperla). Evolution 1985, 39, 965-984.

3. Henry, C.S.; Brooks, S.J.; Duelli, P.; Johnson, J.B.; Wells, M.M.; Mochizuki, A. Obligatory duetting behaviour in the chrysoperla carnea-Group of cryptic species (neuroptera: Chrysopidae): Its role in shaping evolutionary history. Biol. Rev. 2013, 88, 787-808. [CrossRef] [PubMed]

4. Canard, M.; Semeria, Y.; New, T. Biology of Chrysopidae; Springer: Dordrecht, The Netherlands, 1984.

5. McEwen, P.K.; New, T.R.; Whittington, A.E. Lacewings in the Crop Environment; Cambridge University Press: Cambridge, UK, 2007.

6. Hagley, E.; Miles, N. Release of chrysoperla carnea stephens (neuroptera: Chrysopidae) for control of tetranychus urticae koch (acarina: Tetranychidae) on peach grown in a protected environment structure. Can. Entomol. 1987, 119, 205-206. [CrossRef]

7. Hommen, U.; Baveco, J.; Galic, N.; van den Brink, P.J. Potential application of ecological models in the european environmental risk assessment of chemicals i: Review of protection goals in eu directives and regulations. Integr. Environ. Assess. Manag. 2010, 6, 325-337. [CrossRef] [PubMed]

8. Bigler, F. Biological control by chrysopids: Intergration with pesticides. In Biology of Chrysopidae; Canard, M., Semeria, Y., New, T., Eds.; Springer: Dordrecht, The Netherlands, 1984; Volume 27, pp. 233-245.

9. Tsuchida, T.; Koga, R.; Horikawa, M.; Tsunoda, T.; Maoka, T.; Matsumoto, S.; Simon, J.-C.; Fukatsu, T. Symbiotic bacterium modifies aphid body color. Science 2010, 330, 1102-1104. [CrossRef]

10. Werren, J.H.; Baldo, L.; Clark, M.E. Wolbachia: Master manipulators of invertebrate biology. Nat. Rev. Microbiol. 2008, 6, 741-751. [CrossRef]

11. Aksoy, S. Tsetse-a haven for microorganisms. Parasitol. Today 2000, 16, 114-118. [CrossRef]

12. Sandström, J.P.; Russell, J.A.; White, J.P.; Moran, N.A. Independent origins and horizontal transfer of bacterial symbionts of aphids. Mol. Ecol. 2001, 10, 217-228. [CrossRef]

13. Baldo, L.; Ayoub, N.A.; Hayashi, C.Y.; Russell, J.A.; Stahlhut, J.K.; Werren, J.H. Insight into the routes of wolbachia invasion: High levels of horizontal transfer in the spider genus agelenopsis revealed by wolbachia strain and mitochondrial DNA diversity. Mol. Ecol. 2008, 17, 557-569. [CrossRef]

14. Weinert, L.A.; Araujo-Jnr, E.V.; Ahmed, M.Z.; Welch, J.J. The Incidence of Bacterial Endosymbionts in Terrestrial Arthropods. Proc. R. Soc. 2015, 282, 20150249. [CrossRef] [PubMed]

15. Weinert, L.A.; Werren, J.H.; Aebi, A.; Stone, G.N.; Jiggins, F.M. Evolution and diversity of rickettsia bacteria. BMC Biol. 2009, 7, 6. [CrossRef] [PubMed]

16. Cowdry, E.V. The distribution of rickettsia in the tissues of insects and arachnids. J. Exp. Med. 1923, 37, 431-456. [CrossRef] [PubMed] 
17. Gross, L. How charles nicolle of the pasteur institute discovered that epidemic typhus is transmitted by lice: Reminiscences from my years at the pasteur institute in paris. Proc. Natl. Acad. Sci. USA 1996, 93, 10539-10540. [CrossRef] [PubMed]

18. Davis, M.J.; Ying, Z.; Brunner, B.R.; Pantoja, A.; Ferwerda, F.H. Rickettsial relative associated with papaya bunchy top disease. Curr. Microbiol. 1998, 36, 80-84. [CrossRef]

19. Kikuchi, Y.; Sameshima, S.; Kitade, O.; Kojima, J.; Fukatsu, T. Novel clade of rickettsia spp. From leeches. Appl. Environ. Microbiol. 2002, 68, 999-1004. [CrossRef]

20. Miller, M.W.; Lohr, K.E.; Cameron, C.M.; Williams, D.E.; Peters, E.C. Disease dynamics and potential mitigation among restored and wild staghorn coral, acropora cervicornis. PeerJ 2014, 2, e541. [CrossRef]

21. Modeo, L.; Salvetti, A.; Rossi, L.; Castelli, M.; Szokoli, F.; Krenek, S.; Serra, V.; Sabaneyeva, E.; Di Giuseppe, G.; Fokin, S.I. "Candidatus trichorickettsia mobilis", a rickettsiales bacterium, can be transiently transferred from the unicellular eukaryote paramecium to the planarian dugesia japonica. PeerJ 2020, 8, e8977. [CrossRef]

22. Werren, J.H.; Hurst, G.; Zhang, W.; Breeuwer, J.; Stouthamer, R.; Majerus, M. Rickettsial relative associated with male killing in the ladybird beetle (adalia bipunctata). J. Bacteriol. 1994, 176, 388-394. [CrossRef]

23. Lawson, E.T.; Mousseau, T.A.; Klaper, R.; Hunter, M.D.; Werren, J.H. Rickettsia associated with male-killing in a buprestid beetle. Heredity 2001, 86, 497-505. [CrossRef]

24. Hagimori, T.; Abe, Y.; Date, S.; Miura, K. The first finding of a rickettsia bacterium associated with parthenogenesis induction among insects. Curr. Microbiol. 2006, 52, 97-101. [CrossRef] [PubMed]

25. Giorgini, M.; Bernardo, U.; Monti, M.; Nappo, A.; Gebiola, M. Rickettsia symbionts cause parthenogenetic reproduction in the parasitoid wasp pnigalio soemius (hymenoptera: Eulophidae). Appl. Environ. Microbiol. 2010, 76, 2589-2599. [CrossRef] [PubMed]

26. Himler, A.G.; Adachi-Hagimori, T.; Bergen, J.E.; Kozuch, A.; Kelly, S.E.; Tabashnik, B.E.; Chiel, E.; Duckworth, V.E.; Dennehy, T.J.; Zchori-Fein, E. Rapid spread of a bacterial symbiont in an invasive whitefly is driven by fitness benefits and female bias. Science 2011, 332, 254-256. [CrossRef] [PubMed]

27. Chiel, E.; Gottlieb, Y.; Zchori-Fein, E.; Mozes-Daube, N.; Katzir, N.; Inbar, M.; Ghanim, M. Biotype-dependent secondary symbiont communities in sympatric populations of bemisia tabaci. Bull. Entomol. Res. 2007, 97, 407-413. [CrossRef] [PubMed]

28. Hayashi, M.; Nomura, M.; Kageyama, D. Rapid comeback of males: Evolution of male-killer suppression in a green lacewing population. Proc. R. Soc. B 2018, 285, 20180369. [CrossRef]

29. Hayashi, M.; Watanabe, M.; Yukuhiro, F.; Nomura, M.; Kageyama, D. A nightmare for males? A maternally transmitted male-killing bacterium and strong female bias in a green lacewing population. PLoS ONE 2016, 11, e0155794. [CrossRef]

30. Gerth, M.; Wolf, R.; Bleidorn, C.; Richter, J.; Sontowski, R.; Unrein, J.; Schlegel, M.; Gruppe, A. Green lacewings (neuroptera: Chrysopidae) are commonly associated with a diversity of rickettsial endosymbionts. Zool. Lett. 2017, 3, 12. [CrossRef]

31. Williams, K.P.; Gillespie, J.J.; Sobral, B.W.; Nordberg, E.K.; Snyder, E.E.; Shallom, J.M.; Dickerman, A.W. Phylogeny of gammaproteobacteria. J. Bacteriol. 2010, 192, 2305-2314. [CrossRef]

32. Aksoy, S.; Chen, X.-A.; Hypsa, V. Phylogeny and potential transmission routes of midgut-associated endosymbionts of tsetse (diptera: Glossinidae). Insect Mol. Biol. 1997, 6, 183-190. [CrossRef]

33. Kaiwa, N.; Hosokawa, T.; Kikuchi, Y.; Nikoh, N.; Meng, X.Y.; Kimura, N.; Ito, M.; Fukatsu, T. Primary gut symbiont and secondary, sodalis-allied symbiont of the scutellerid stinkbug cantao ocellatus. Appl. Environ. Microbiol. 2010, 76, 3486-3494. [CrossRef]

34. Nováková, E.; Hypša, V. A new sodalis lineage from bloodsucking fly craterina melbae (diptera, hippoboscoidea) originated independently of the tsetse flies symbiont sodalis glossinidius. FEMS Microbiol. Lett. 2007, 269, 131-135. [CrossRef] [PubMed]

35. Vigneron, A.; Masson, F.; Vallier, A.; Balmand, S.; Rey, M.; Vincent-Monégat, C.; Aksoy, E.; Aubailly-Giraud, E.; Zaidman-Rémy, A.; Heddi, A. Insects recycle endosymbionts when the benefit is over. Curr. Biol. 2014, 24, 2267-2273. [CrossRef] [PubMed]

36. Fukatsu, T.; Koga, R.; Smith, W.A.; Tanaka, K.; Nikoh, N.; Sasaki-Fukatsu, K.; Yoshizawa, K.; Dale, C.; Clayton, D.H. Bacterial endosymbiont of the slender pigeon louse, columbicola columbae, allied to endosymbionts of grain weevils and tsetse flies. Appl. Environ. Microbiol. 2007, 73, 6660-6668. [CrossRef] [PubMed] 
37. Hosokawa, T.; Kaiwa, N.; Matsuura, Y.; Kikuchi, Y.; Fukatsu, T. Infection prevalence of sodalis symbionts among stinkbugs. Zool. Lett. 2015, 1, 5. [CrossRef] [PubMed]

38. Šochová, E.; Husník, F.; Nováková, E.; Halajian, A.; Hypša, V. Arsenophonus and sodalis replacements shape evolution of symbiosis in louse flies. PeerJ 2017, 5, e4099. [CrossRef]

39. Dale, C.; Welburn, S. The endosymbionts of tsetse flies: Manipulating host-parasite interactions. Int. J. Parasitol. 2001, 31, 628-631. [CrossRef]

40. Enomoto, S.; Chari, A.; Clayton, A.L.; Dale, C. Quorum sensing attenuates virulence in sodalis praecaptivus. Cell Host Microbe. 2017, 21, 629-636.e625. [CrossRef]

41. Gottlieb, Y.; Ghanim, M.; Chiel, E.; Gerling, D.; Portnoy, V.; Steinberg, S.; Tzuri, G.; Horowitz, A.R.; Belausov, E.; Mozes-Daube, N. Identification and localization of a rickettsia sp. In bemisia tabaci (homoptera: Aleyrodidae). Appl. Environ. Microbiol. 2006, 72, 3646-3652. [CrossRef]

42. Ayoubi, A.; Talebi, A.A.; Fathipour, Y.; Mehrabadi, M. Coinfection of the secondary symbionts, hamiltonella defensa and arsenophonus sp. Contribute to the performance of the major aphid pest, aphis gossypii (hemiptera: Aphididae). Insect Sci. 2018, 27, 86-98. [CrossRef]

43. Meyer, M.; Kircher, M. Illumina sequencing library preparation for highly multiplexed target capture and sequencing. Cold Spring Harb. Protoc. 2010, 2010, pdb. prot5448. [CrossRef]

44. Kircher, M. Analysis of high-throughput ancient DNA sequencing data. Anc. DNA Methods Protoc. 2012, 197-228.

45. Renaud, G.; Kircher, M.; Stenzel, U.; Kelso, J. Freeibis: An efficient basecaller with calibrated quality scores for illumina sequencers. Bioinformatics 2013, 29, 1208-1209. [CrossRef] [PubMed]

46. Peng, Y.; Leung, H.C.; Yiu, S.-M.; Chin, F.Y. Idba-ud: A de novo assembler for single-cell and metagenomic sequencing data with highly uneven depth. Bioinformatics 2012, 28, 1420-1428. [CrossRef] [PubMed]

47. Sedlazeck, F.J.; Rescheneder, P.; von Haeseler, A. Nextgenmap: Fast and accurate read mapping in highly polymorphic genomes. Bioinformatics 2013, 29, 2790-2791. [CrossRef]

48. García-Alcalde, F.; Okonechnikov, K.; Carbonell, J.; Cruz, L.M.; Götz, S.; Tarazona, S.; Dopazo, J.; Meyer, T.F.; Conesa, A. Qualimap: Evaluating next-generation sequencing alignment data. Bioinformatics 2012, 28, 2678-2679. [CrossRef]

49. Bankevich, A.; Nurk, S.; Antipov, D.; Gurevich, A.A.; Dvorkin, M.; Kulikov, A.S.; Lesin, V.M.; Nikolenko, S.I.; Pham, S.; Prjibelski, A.D. Spades: A new genome assembly algorithm and its applications to single-cell sequencing. J. Comput. Biol. 2012, 19, 455-477. [CrossRef]

50. Katoh, K.; Standley, D.M. Mafft multiple sequence alignment software version 7: Improvements in performance and usability. Mol. Biol. Evol. 2013, 30, 772-780. [CrossRef]

51. Sela, I.; Ashkenazy, H.; Katoh, K.; Pupko, T. Guidance2: Accurate detection of unreliable alignment regions accounting for the uncertainty of multiple parameters. Nucleic Acids Res. 2015, 43, W7-W14. [CrossRef]

52. Nguyen, L.-T.; Schmidt, H.A.; von Haeseler, A.; Minh, B.Q. Iq-tree: A fast and effective stochastic algorithm for estimating maximum-likelihood phylogenies. Mol. Biol. Evol. 2014, 32, 268-274. [CrossRef]

53. R Core Team. R: A Language and Environment for Statistical Computing; R Foundation for Statistical Computing: Vienna, Austria, 2015.

54. Untergasser, A.; Cutcutache, I.; Koressaar, T.; Ye, J.; Faircloth, B.C.; Remm, M.; Rozen, S.G. Primer3-New capabilities and interfaces. Nucleic Acids Res. 2012, 40, e115. [CrossRef]

55. Liu, C.; Mao, J.; Zeng, F. Chrysopa septempunctata (neuroptera: Chrysopidae) vitellogenin functions through effects on egg production and hatching. J. Econ. Entomol. 2015, 108, 2779-2788. [CrossRef] [PubMed]

56. Caspi-Fluger, A.; Inbar, M.; Steinberg, S.; Friedmann, Y.; Freund, M.; Mozes-Daube, N.; Zchori-Fein, E. Characterization of the symbiont rickettsia in the mirid bug nesidiocoris tenuis (reuter)(heteroptera: Miridae). Bull. Entomol. Res. 2014, 104, 681-688. [CrossRef]

57. Dale, C.; Maudlin, I. Sodalis gen. Nov. And sodalis glossinidius sp. Nov., a microaerophilic secondary endosymbiont of the tsetse fly glossina morsitans morsitans. Int. J. Syst. Evol. Microbiol. 1999, 49, 267-275. [CrossRef]

58. Koga, R.; Moran, N.A. Swapping symbionts in spittlebugs: Evolutionary replacement of a reduced genome symbiont. ISME J. 2014, 8, 1237-1246. [CrossRef]

59. Saeed, A.; White, J.A. Surveys for maternally-inherited endosymbionts reveal novel and variable infections within solitary bee species. J. Invertebr. Pathol. 2015, 132, 111-114. [CrossRef] [PubMed] 
60. Hedges, L.M.; Brownlie, J.C.; O'neill, S.L.; Johnson, K.N. Wolbachia and virus protection in insects. Science 2008, 322, 702. [CrossRef] [PubMed]

61. Doudoumis, V.; Tsiamis, G.; Wamwiri, F.; Brelsfoard, C.; Alam, U.; Aksoy, E.; Dalaperas, S.; Abd-Alla, A.; Ouma, J.; Takac, P. Detection and characterization of wolbachia infections in laboratory and natural populations of different species of tsetse flies (genus glossina). BMC Microbiol. 2012, 12, S3. [CrossRef]

62. Hoffmann, A.A.; Turelli, M.; Harshman, L.G. Factors affecting the distribution of cytoplasmic incompatibility in drosophila simulans. Genetics 1990, 126, 933-948. [PubMed]

63. Prado, S.S.; Golden, M.; Follett, P.A.; Daugherty, M.P.; Almeida, R.P. Demography of gut symbiotic and aposymbiotic nezara viridula 1.(hemiptera: Pentatomidae). Environ. Entomol. 2009, 38, 103-109. [CrossRef]

64. Toju, H.; Fukatsu, T. Diversity and infection prevalence of endosymbionts in natural populations of the chestnut weevil: Relevance of local climate and host plants. Mol. Ecol. 2011, 20, 853-868. [CrossRef]

65. Snyder, A.K.; McMillen, C.M.; Wallenhorst, P.; Rio, R.V. The phylogeny of sodalis-like symbionts as reconstructed using surface-encoding loci. FEMS Microbiol. Lett. 2011, 317, 143-151. [CrossRef]

66. Santos-Garcia, D.; Silva, F.J.; Morin, S.; Dettner, K.; Kuechler, S.M. The all-rounder sodalis: A new bacteriome-associated endosymbiont of the lygaeoid bug henestaris halophilus (heteroptera: Henestarinae) and a critical examination of its evolution. Genome Biol. Evol. 2017, 9, 2893-2910. [CrossRef] [PubMed]

67. Chari, A.; Oakeson, K.F.; Enomoto, S.; Jackson, D.G.; Fisher, M.A.; Dale, C. Phenotypic characterization of sodalis praecaptivus sp. Nov., a close non-insect-associated member of the sodalis-allied lineage of insect endosymbionts. Int. J. Syst. Evol. Microbiol. 2015, 65, 1400-1405. [CrossRef] [PubMed]

68. Clayton, A.L.; Oakeson, K.F.; Gutin, M.; Pontes, A.; Dunn, D.M.; von Niederhausern, A.C.; Weiss, R.B.; Fisher, M.; Dale, C. A novel human-infection-derived bacterium provides insights into the evolutionary origins of mutualistic insect-bacterial symbioses. PLoS Genet. 2012, 8, e1002990. [CrossRef] [PubMed]

69. Oakeson, K.F.; Gil, R.; Clayton, A.L.; Dunn, D.M.; von Niederhausern, A.C.; Hamil, C.; Aoyagi, A.; Duval, B.; Baca, A.; Silva, F.J.; et al. Genome degeneration and adaptation in a nascent stage of symbiosis. Genome Biol. Evol. 2014, 6, 76-93. [CrossRef] [PubMed]

70. Toh, H.; Weiss, B.L.; Perkin, S.A.; Yamashita, A.; Oshima, K.; Hattori, M.; Aksoy, S. Massive genome erosion and functional adaptations provide insights into the symbiotic lifestyle of sodalis glossinidius in the tsetse host. Genome Res. 2006, 16, 149-156. [CrossRef]

71. Rosas-Pérez, T.; de León, A.V.-P.; Rosenblueth, M.; Ramírez-Puebla, S.T.; Rincón-Rosales, R.; Martínez-Romero, J.; Dunn, M.F.; Kondorosi, É.; Martínez-Romero, E. The symbiome of llaveia cochineals (hemiptera: Coccoidea: Monophlebidae) includes a gammaproteobacterial cosymbiont sodalis tme1 and the known candidatus walczuchella monophlebidarum. In Insect Physiology and Ecology; IntechOpen: London, UK, 2017.

72. Silva, F.J.; Latorre, A.; Gómez-Valero, L.; Moya, A. Genomic changes in bacteria: From free-living to endosymbiotic life. In Structural Approaches to Sequence Evolution; Springer: Berlin/Heidelberg, Germany, 2007; pp. 149-165.

73. Kondo, N.; Shimada, M.; Fukatsu, T. Infection density of wolbachia endosymbiont affected by co-infection and host genotype. Biol. Lett. 2005, 1, 488-491. [CrossRef]

74. Goto, S.; Anbutsu, H.; Fukatsu, T. Asymmetrical interactions between wolbachia and spiroplasma endosymbionts coexisting in the same insect host. Appl. Environ. Microbiol. 2006, 72, 4805-4810. [CrossRef]

75. Balmand, S.; Lohs, C.; Aksoy, S.; Heddi, A. Tissue distribution and transmission routes for the tsetse fly endosymbionts. J. Invertebr. Pathol. 2013, 112, S116-S122. [CrossRef]

76. Cheng, Q.; Aksoy, S. Tissue tropism, transmission and expression of foreign genes in vivo in midgut symbionts of tsetse flies. Insect Mol. Biol. 1999, 8, 125-132. [CrossRef]

77. Chen, D.Q.; Montllor, C.B.; Purcell, A.H. Fitness effects of two facultative endosymbiotic bacteria on the pea aphid, acyrthosiphon pisum, and the blue alfalfa aphid, a. Kondoi. Entomol. Exp. Et Appl. 2000, 95, 315-323. [CrossRef]

78. Sakurai, M.; Koga, R.; Tsuchida, T.; Meng, X.-Y.; Fukatsu, T. Rickettsia symbiont in the pea aphid acyrthosiphon pisum: Novel cellular tropism, effect on host fitness, and interaction with the essential symbiont buchnera. Appl. Environ. Microbiol. 2005, 71, 4069-4075. [CrossRef] [PubMed] 
79. Farikou, O.; Njiokou, F.; Mbida, J.A.M.; Njitchouang, G.R.; Djeunga, H.N.; Asonganyi, T.; Simarro, P.P.; Cuny, G.; Geiger, A. Tripartite interactions between tsetse flies, sodalis glossinidius and trypanosomes-An epidemiological approach in two historical human african trypanosomiasis foci in cameroon. Infect. Genet. Evol. 2010, 10, 115-121. [CrossRef]

80. Welburn, S.; Maudlin, I. Tsetse-trypanosome interactions: Rites of passage. Parasitol. Today 1999, 15, $399-403$. [CrossRef]

81. Liu, X.-D.; Lei, H.-X.; Chen, F.-F. Infection pattern and negative effects of a facultative endosymbiont on its insect host are environment-dependent. Sci. Rep. 2019, 9, 4013. [CrossRef]

82. Zytynska, S.E.; Thighiouart, K.; Frago, E. A meta-analysis on the benefits and costs of hosting secondary endosymbionts in sap-sucking insects. bioRxiv 2019, 563031. [CrossRef]

83. Boyd, B.M.; Allen, J.M.; Koga, R.; Fukatsu, T.; Sweet, A.D.; Johnson, K.P.; Reed, D.L. Two bacterial genera, sodalis and rickettsia, associated with the seal louse proechinophthirus fluctus (phthiraptera: Anoplura). Appl. Environ. Microbiol. 2016, 82, 3185-3197. [CrossRef]

84. Skaljac, M.; Zanic, K.; Ban, S.G.; Kontsedalov, S.; Ghanim, M. Co-infection and localization of secondary symbionts in two whitefly species. BMC Microbiol. 2010, 10, 142. [CrossRef]

Publisher's Note: MDPI stays neutral with regard to jurisdictional claims in published maps and institutional affiliations.

(C) 2020 by the authors. Licensee MDPI, Basel, Switzerland. This article is an open access article distributed under the terms and conditions of the Creative Commons Attribution (CC BY) license (http://creativecommons.org/licenses/by/4.0/). 